\title{
İMPLANT DESTEKLİ OVERDENTURE PROTEZLERDE KULLANILAN HASSAS TUTUCULAR
}

\section{PRECİSIOON ATTACHMENTS USED ON THE IMPLANT-RETAİNED OVERDENTURES}

\author{
Dt. Mustafa SOLMAZGÜL*
}

Prof. Dr. Arife DOĞAN*

\author{
Makale Kodu/Article code: 4121 \\ Makale Gönderilme tarihi: 22.07.2019 \\ Kabul Tarihi: 20.11.2019
}

DOI : $10.17567 /$ ataunidfd.649191

Mustafa Solmazgül: ORCID ID: 0000-0003-0001-1351

Arife Doğan: ORCID ID: 0000-0002-9572-5447

Öz

Geleneksel diş hekimliği dişsiz hastalar için sınırlı tedavi seçenekleri sunar; protezlerin tasarımı doğrudan mevcut ağız koşullarıyla belirlenir. Ancak, tam protez kullanan bazı hastalar retansiyon veya stabilite kaybı, fonksiyonda düşüş, konuşma güçlüğü, doku duyarlıı̆ı veya yumuşak doku değişikliğinden dolayı sorunlar yaşar. Son yıllarda, implant diş hekimliği giderek önem kazanmıştır ve bu alandaki teknik gelişmelerle hastaların memnuniyetini sağlamak üzere çok sayıda tedavi yolları ortaya çıkmıştır. Çoğu vakada, implant-tutuculu overdenture uygulamaları, yalnızca alveolar dokularca desteklenen konvansiyonel tam protezlere karşı daha iyi bir seçenektir. İmplant-tutuculu overdenture yapımında kullanılan pek çok ataçman sistemi vardır ve protezlerin başarısı için her birinin özellik ve endikasyonlarının bilinmesi oldukça önemlidir. Bu derlemenin amacı, bu alanda yapılan çalışma sonuçları ışığında implant-tutuculu tam protezlerde kullanılan ataçman sistemlerin seçiminde klinisyenlere yardımcı olabilmektir. Anahtar Kelimeler: Diş implantı; implant destekli protez; hassas tutuculu protez

\section{ABSTRACT}

Traditional dentistry provides limited treatment options for the edentulous patients; the design of the dentures is determined directly to the existing oral conditions. However, many patients using complete dentures experience problems because of lack of retention or stability, decrease in function, difficulties in speech, tissue sensitivity or soft tissue changes. Recently, more attention has been drawn to implant dentistry, and with the technical developments on this field, a number of treatment modalities improving patients' satisfaction are available. In most instances, implant-retained overdentures are a superior alternative to a conventional type of complete denture supported only by the alveolar tissues. There are many attachment systems to fabricate implant-retained overdentures, and for the success of dentures it is of primary importantce to know the properties and indications of each one. The purpose of this review is to help clinicians in selecting attacments systems used with implant-retained complete dentures in the light of the results of the studies made on this field.

Keywords: Dental implant; implant-supported denture; denture precision attachment

* Gazi Üniversitesi, Diş Hekimliği Fakültesi, Protetik Diș Tedavisi AD, Ankara

Kaynakça Bilgisi: Solmazgül M, Doğan A. İmplant Destekli Overdenture Protezlerde Kullanılan Hassas Tutucular. Atatürk Üniv Diş Hek Fak Derg 2020; 30: 519-27. Citation Information: Solmazgul M, Dogan A. Precision Attachments Used on the Implant-Retained Overdentures. J Dent Fac Atatürk Uni $2020 ; 30: 519-27$.

\section{GİRİş}

Diş hekimliğinin temel amacl, hastanın oral bölgesinde normal konturları, fonksiyonu, fonasyonu, estetiği ve ağız sağlığını yeniden sağlamaktır, ancak kaybedilen diş sayısı arttıkça başarıya ulaşmak da o denli zor olmaktadır. Mevcut araştırma sonuçları, geliştirilen tanısal aletler, doğru tedavi planlaması, implant tasarım, materyal ve yapım teknikleri sayesinde çok sayıda tedavisi güç vakanın rehabilitasyonunun başarı ile gerçekleştiğini göstermektedir.

Doğal dişlerle yapılan çiğneme fonksiyonu, hareketli protezler kullanıldığında \%60 oranında azal- maktadır. İmplant üstü bir protez azalan fonksiyonu normal sınırlara yaklaştırabilir. Dişsiz hastaların estetik görünümleri kemik atrofisine bağlı olarak önemli oranda değişim gösterir. İmplantlar, kemiği stimüle ederek sağlıklı dişlere benzer şekilde kemik hacmi ve boyutlarının korunmasını sağlar; sonuç olarak yüz şekli, destek kemik dokusunun korunmasına bağlı olarak değişime uğramaz. Dişsiz hastaların yumuşak dokuları, mukozanın incelmesi, tükürük akışının azalması, protezin retansiyon ve stabilitesini kaybetmesinden dolayı dış etkilere karşı daha duyarlı hale gelmiş durumdadır. ${ }^{1}$ Böyle durumlarda geleneksel tam protezlerden memnun kalmayan tam dişsiz hastalar için, implantlar 
artık neredeyse standart bir tedavi seçeneği olmuştur ve vakalar implant destekli sabit protezler; hibrit protezler veya implant destekli hareketli protezlerle hasta memnuniyetini artıracak şekilde rehabilite edilebilir. ${ }^{2}$

\section{IMPLANT DESTEKLI HAREKETLI PROTEZLER (OVERDENTURE)}

Tam dişsiz hastaların en büyük problemi, geleneksel tam protezlerinden kaynaklı fonksiyonel memnuniyetsizliklerinin olmasıdır. Bunlar, özellikle alt protezlerden kaynaklanan uyum sorunu, retansiyon ve stabilite kaybı, ağrı ve acı hissidir. Hastaların implant destekli overdenture uygulamalarında geleneksel tam protezlere göre daha az çiğneme güçlüğü yaşadığı bildirilmiştir. $^{3}$

Mc Gill Konsensüne göre tam dişsiz mandibulada implant destekli mandibular overdenture ilk tedavi seçeneğidir ve 2 implant destekli overdenture standart tedavi planıdır. ${ }^{4}$

İmplant destekli overdenture uygulaması, klinik olarak yapım aşamasında daha az süre gerektirdiğinden yaşlı hastalarda daha güvenilirdir. Mevcut kemik dokusunun riskli olduğu hastalarda da uygulanabilir. İmplantın ağızda kalım oranı implant destekli sabit protezlerinki ile benzerdir. ${ }^{5}$ Bununla birlikte, bu tip uygulamalar hastanın takıp çıkarılan bir protez kullanmak istememesi; çeneler arası belirli bir mesafe gerektirmesi; uzun dönem bakım gerektirmesi (tutucu değişimi, besleme gerekliliği vb); kemik yıkımının posterior bölgede devam etmesi; protezin altına gıda artıklarının kaçması; protezin hareket etmesi ve hassas tutucuların plastik parçaları veya klipslerinin hasar, yıpranma ve kırık nedeniyle belli aralıklarla yenilenmesinin gerekmesi gibi bazı dezavantajlara sahiptir. ${ }^{1}$

İmplant overdenture uygulamaları, implant sayı ve dağılımına göre mukoza destekli, implant destekli veya implant-mukoza destekli /tutuculu olacak şekilde literatürde sınıflandırılmıştır. $^{6}$

\section{Implant uygulamalarında kullanılan hassas tutucular} destekli

İmplant destekli overdenture uygulamalarında değişik tipte hassas tutucular kullanılabilir. Hastanın ağız hijyeni, anatomik koşullar (alt-üst çene farkı, karşıt ark dentisyonu, interokluzal mesafe), implantlar arası mesafe, retansiyon ihtiyacı, biyomekanik etkenler, hastanın psikolojik durumu ve beklentileri, hastanın sosyal statüsü ve ekonomik koşullar, hassas tutucu seçimini etkileyen faktörlerdir. Ayrıca, destek sayısı ve kretteki dağılımı, implantların çapı ve uzunluğu, kret kalınlığı, alveoler kretin formu ve rezorpsiyon miktarı da göz önünde bulundurulması gereken diğer hususlardır. ${ }^{7,8}$
İmplant destekli overdenture uygulamalarında çiğneme kuvveti protez kaidesine destek olan mukoza ve implantlar arasında dağılır. Bu kuvvet dağılımı kullanılan hassas tutucu tipine ve mukozanın yer değiştirme miktarına bağlı olarak farklılık gösterir. ${ }^{9}$ Her bir vaka kendine has özellikleri barındırır; hastanın beklentileri ve istekleri, uzun dönemde ortaya çıkması beklenen biyolojik ve fonksiyonel sonuçlar en iyi şekilde değerlendirilmelidir. ${ }^{8}$ İmplant üstü hareketli protezlerle genelde bar, stud, manyetik veya teleskopik hassas tutucular kullanilır.

\section{Bar Tutucular}

Bar tutucular, iki ya da daha fazla implantı birbirine bağlayan ünitelerdir. Stud tutuculara nazaran daha iyi tutuculuk ve stabilite sağlar. ${ }^{10}$ Spiekermann ve arkadaşları ${ }^{11}$, bar tutucuları, "U" şeklinde kesitli (okluzal yüz yuvarlatılmış paralel kenarlı bar), yuvarlak kesitli (round bar) ve oval kesitli (Dolder bar) olmak üzere, kesit şekillerine göre üç sınıfa ayırmışlardır. U şeklinde kesitli bar, rijit yapıdadır ve implantları düz bir hatta birleştirir; Kennedy Sınıf 3 gibi kısmi dişsizlik vakalarında dört dayanak varlığında kullanımı uygundur. Yuvarlak kesitli barın esnek ya da rijit tipleri mevcuttur. Dayanaklara iletilen yatay ve lateral kuvvetlerin miktarını azaltır ve protez kaidesinin vertikal yönde hareketine daha çok imkan tanır ve $U$ şeklinde kesitli barlara kıyasla implantlar üzerinde daha az tork oluşturur. ${ }^{12}$ Öte yandan, oval kesitli bar da esnek veya rijit tipte mevcuttur ve stres kırıcılık ve indirekt tutuculuk özelliğine sahiptir.

$\mathrm{Bu}$ bar tiplerinin dışında, yarı esnek karakterde Hader bar da sıklıkla kullanılan bir bar türüdür (Şekil 1).

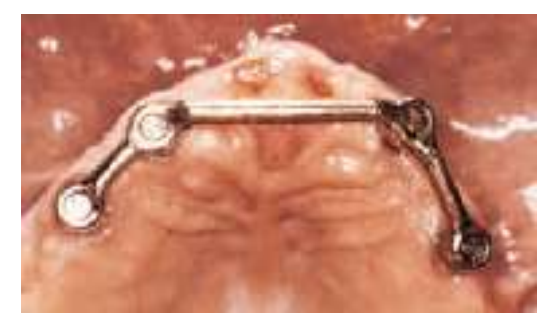

Şekil 1. Hader bar tutucu ${ }^{1}$

Üst kısmı yuvarlaktır ve dokuya doğru uzanır, etek olarak da ifade edilen kısmıyla kesiti anahtar deliğine benzer. Hader barın doku uzantısı barın dayanıkııığını artırırken esnekliğini azaltır. Ayrıca millenmiş bar, paralel kenarlı bar, simante edilen bar ve elektroforez ile tutuculuğun sağlandığı bar tipleri de klinik uygulamada yer bulmaktadır. ${ }^{13}$ Barların prefabrik olan- 
larının yanı sıra kişiye özel kişisel barlar da hazırlanabilir. Daha ucuz ve dayanaklı olan prefabrik barlar, millenmiş ya da kişisel barlar yerine sıklıkla tercih edilmektedir. Kişisel barlarda kret şekline ve dil boşluğuna göre uyumlama yapılabilir. ${ }^{14}$ Ayrıca kişisel barların ball, locator, O-ring ve ERA gibi stud tutucularla kombine tasarımlarda da kullanılması mümkündür. Bar tutucu klipslerinin uygun şekilde yerleştirilmesine olanak tanımayan yetersiz bir mesafe varlığında millenmiş barların kullanımı tavsiye edilmektedir. ${ }^{15}$

Barlar, overdenture proteze klips adı verilen küçük bağlantı parçalarıyla bağlanır. Bu klipsler metal veya plastikten olabilir. Plastik klipslerle karşılaştırıldığında, metal olanlar daha fazla aşınma direncine sahiptir. Metal klips kullanımı sayesinde, barın boyutları daha da küçültülebilir, ancak metal klipsi değiştirmek için protezden bir frez yardımıyla aşındırılması gerekir. Öte yandan plastik olanlar daha kolay çıkartılabilir. ${ }^{12}$

\section{Bar Düzenlemesinin Esasları}

Genel bir kural olarak, eğer tek parça bar kullanılacaksa, iki adet klips veya oturan kıskaç (eyer) parçaların yerleştirilebilmesi için barın ideal uzunluğunun 20-22 mm olması gereklidir. Bu, standart $4 \mathrm{~mm}$ çapında implantların kullanılması durumunda, implantların merkezleri arasındaki mesafenin 24-26mm arasında olması gerektiği anlamına gelir. Eğer destek olarak kullanılacak implantlar birbirine çok yakın olursa, araya yerleştirilecek kısa bar, overdenture protez için yeterli düzeyde retansiyon ve stabilizasyon sağlamayacaktır. $\mathrm{Bu}$ mesafe, mandibular arkın uzunluğu ve kavsi ile tutucu grubunun tipine bağlı olarak belirlenir. Eğer implantlar tam tersi olarak distale doğru birbirinden aşırı uzakta konumlanacak olursa, düz bir hat şeklinde yerleştirilecek bar, dilin yerleştiği alanı işgal ederek protezin hazırlanması sırasında problemlere yol açacak ve barın eğilmesine neden olacaktır (Şekil 2).

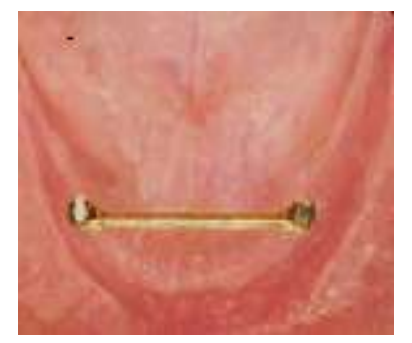

Şekil 2. Distale doğru düz bir hat şeklinde yerleştirilen bar $^{1}$
Bar yapı diagonal (çaprazlama) bir şekilde konumlandırılmışsa, protezin sürtünmesiz bir şekilde anterior yöndeki menteşe hareketine izin vermeyecektir. Bu durum, destek olarak kullanılan implantlar üzerinde aşırı devirme yüklerine neden olacaktır (Şekil 3).

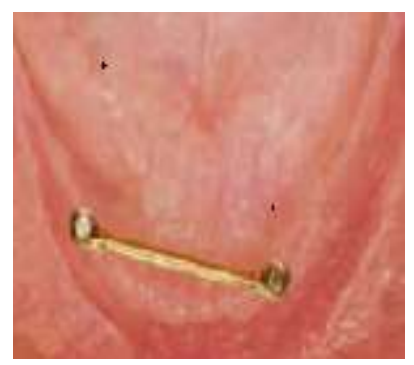

Şekil 3. Diagonal şekilde yerleştirilen bar $^{1}$

Genel bir kural olarak bar, sağ ve sol posterior mandibular ark segmentleri arasındaki açıyı ikiye bölen hatta (açıortaya) dik olmalıdır. İdeal olan barın alt kenarı ile yumuşak doku arasında en az $2 \mathrm{~mm}$ mesafe olmasıdır. Bu mesafe temizlikte uygulanan fırçalar gibi enstrümanlar için olduğu kadar, tükürük ve gıda artıklarının da kolay bir şekilde barın altından geçişini sağlar. Barın alveolar kret tepesinin üzerine denk gelecek şekilde konumlandırılması, barın kolayca kullanılmasını ve barın üzerinde protezin rahat bir şekilde hazırlanmasını sağlar. Bar, kret tepesinin lingualinde konumlanırsa dilin alanı işgal edilmiş olur ve dil fonksiyonlarını yerine getiremez. Barın daha labialde konumlanması, dudak desteğine müdahale etmiş olur; her iki durumda da protezin bitirilmesi sorunlara yol açabilir. ${ }^{1}$

Kliniğimizde uygulanan bar tutucu örneği Şekil 4'te gösterilmiştir.

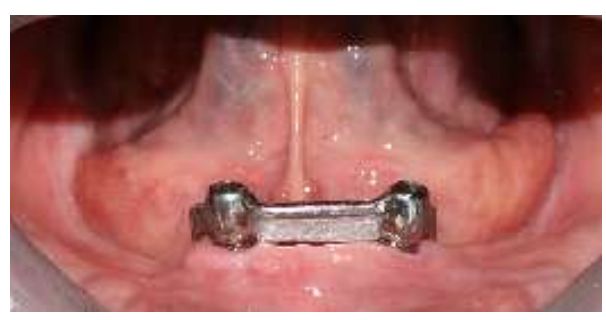

Şekil 4. Bar tutucu

\section{Ön Arka (Anterior-Posterior) Mesafe Kuralı}

Arkın her iki tarafında yer alan en son implantların merkezinden ve en öndeki implantların labiallerinden geçecek şekilde iki hat çizilir; bu iki hat arasındaki mesafe A-P mesafesini verir. Distal kanat uzantısı A-P mesafesinin yarısından daha uzun olmamalıdır (Şekil 5). 


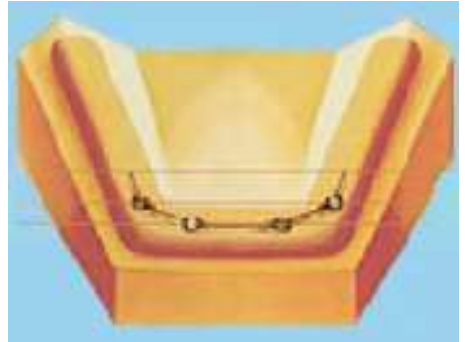

Şekil 5. Ön arka mesafe

Eğer hastanın dört implant yerleşimi için sınırlı şekilde küçük bir alt çeneye sahipse, mental sinirin izin verdiği ölçüde uzağa yerleştirilen arka implantlar A-P mesafesini artırabilir. Böyle durumlarda sağlanan en fazla kanat uzunluğu genellikle 8-12 mm arasındadır. Eğer hasta kare şeklinde bir çene arkına sahipse, implantlar mandibulanın ön bölümünde düz bir hat üzerinde yer alacaktır. Bu durumda A-P mesafesi olmayacağı ya da belirgin bir şekilde azalacağı için herhangi bir kanat tasarımından kaçınmak gerekir. Oval şeklindeki ark formu bir miktar distal kanat uzantısına izin verir. Üçgen şeklinde ark formuna sahip olan hastada A-P mesafesi daha büyüktür ve bu sebeple daha uzun kanat tasarımı uygulanabilir. Bar tutuculu implant destekli overdenture için implant basamağından insizal kenara olan mesafe yaklaşık 12-14 mm olmalıdır. 2- 3 mm'lik yumuşak doku kalınlığı vardır ve bar ile mukoza arasında temizlenebilirlik için $2 \mathrm{~mm}$ 'lik mesafe; bar yüksekliği için 4.5 mm; akrilik rezin ve klip yuvası için $2 \mathrm{~mm}$; dişin kaideden yüksekliği için $3 \mathrm{~mm}$ gerekmektedir. ${ }^{1}$

Mericske-Stern ve arkadaşları ${ }^{16}$ standart bar ve ataçman barla oluşturulan protezlerde kliniksel olarak hasta memnuniyetini değerlendirdikleri çalışmada, her iki grubun da memnuniyet dereceleri yüksek çıkmış, aralarında anlamlı bir fark gözlememişlerdir. Isırma kuvvetleri benzer bulunmuş, ancak ataçmanlı bar ile oluşturulan protezde oblik kuvvetler daha fazla görülmüş ve daha fazla komplikasyon bildirilmiştir. Elsyad ve arkadaşları ${ }^{17}$, farklı bar dizaynlarının retansiyonunu in vitro olarak kıyasladıkları çalışmada Hader bar sisteminin, Dolder bar ve millenmiş bar sitemine kıyasla maksiller implant destekli overdenture uygulamalarında aksiyal kuvvetlere karşı daha iyi retansiyon

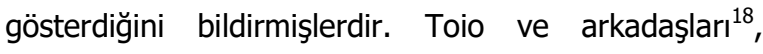
millenmiş bar uyguladıkları protez hastalarının 2 yıl takibi sonucunda vida gevşemesi, vida kırılması, bar kırılması, protez kaidesinin kırılması ve protez kaidesinden dişin ayrılması gibi komplikasyonlar bildirmişlerdir. Rinke ve arkadaşlarının prefabrik yuvarlak kesitli bar, tek parça anterior millenmiş bar ve iki taraflı millenmiş bar olmak üzere 3 farklı bar dizaynını kıyasladıkları klinik çalışmada ${ }^{19}$ en fazla komplikasyon tek parça anterior millenmiş bar uygulanan vakalarda gözlenmiştir.

\section{2-Stud Tutucular}

Stud türü tutucular ana parçanın implanttan uzadığı ekstraradiküler tip ve ana parçanın protez kaidesi içinde yer aldığı intraradiküler tip olarak uygulanabilir. Stud tutucular horizontal ve vertikal yönde belirli derecede esneklik sağlar. ${ }^{20}$

Stud tutucular bar tutucularla benzer yumuşak ve sert doku cevabı gösterir. Uygulamaları daha kolay ve komplikasyonları daha azdır; hijyen sağlanması daha kolay, teknik hassasiyet gerekliliği daha az ve daha ekonomiktir. Ayrıca daha az interark mesafesi gerektirir. Vertikal mesafenin bar yapımına olanak tanımadığı veya implant açı ve konumlarının bar yapımına elverişsiz olduğu durumlarda uygulanabilir. ${ }^{20}$

\section{Ball tutucular}

Ball tutucu sistemleri splintsiz esnek bağlantı sistemleridir. Doku destekli tam dişsizlik olgularında tercih edilir. ${ }^{21}$ Protezin iç kısmına yerleştirilmiş olan bu ataçmanlar implanta sentetik bir plastik halka veya metal bir keple tutunur. Bu tip ataçmanlar protezin yerleştirilmesi esnasında abutmanda bulunan dairesel andırkata yerleşirken gerekli miktarda distorsiyona uğrar. $^{22}$ Destek ile kaide arasındaki düşük miktardaki dikey sıkıştırıcı hareketlere olanak tanır. İmplantların birbirine paralel olarak yerleştirilmesi şart değildir; implantlar arasında $28^{\circ}$ açılanmaya kadar uyumlama kolaylığı sağlar. İmplant açılarının uygun olmadığı durumlarda görülen giriş yolu problemi, matrikslerinin hızlı aşınması ve topuz tutucuların deforme olması gibi dezavantajlara sahiptir. Bar tutucu sistemlerle karşılaştırıldığında, daha kolay uygulanır ve teknik hassasiyet ile ilave laboratuvar işlemleri gerektirmezler. Ayrıca daha az yer kaplar ve daha hijyenik olmalarının yanı sıra maliyetleri de daha düşüktür ve farklı retansiyon derecelerine sahip lastikleri mevcuttur. ${ }^{13}$ Kliniğimizde uygulanan ball tutucu örneği Şekil 6'da gösterilmiştir.

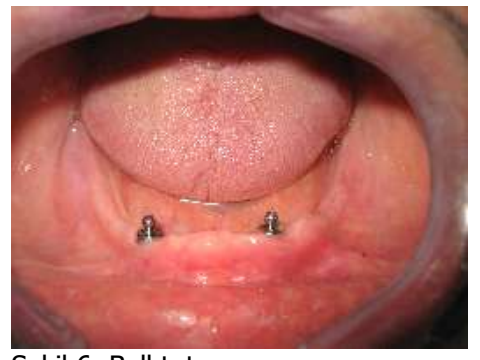

Şekil 6. Ball tutucu 
Ellis ve arkadaşlarının ball tutucu ile mıknatıs tutucuyu kıyasladıkları klinik çalışmada ${ }^{23}$ stabilite ve çiğneme etkinliği açısından ball tutucunun daha iyi sonuç verdiği bildirilmiştir. Sultana ve arkadaşlarının yapmış olduğu locator ve ball ataçman sistemlerini kıyasladıkları in vitro çalışmada ${ }^{24}$ açılı implantlarda ball ataçman sisteminin retansiyonunun daha iyi olduğu bildirilmiştir.

\section{O-ring Tutucular}

Yuvarlak şekilli, ortası delik, sentetik polimer matriks parçası sayesinde devirici kuvvetlere dirençli rezilien tipte bir stud tutucudur. O-ring tutucular implantlar arasındaki $10^{\circ}$ ye kadar paralellikten sapmaya imkan tanır. Daha kalıc retantif kapasite sağlamak için bir matrikste 3 zirkonya topu ve titanyum alaşım yay kullanılarak EZ Lock sistemi geliştirilmiştir. ${ }^{25} \mathrm{Bu}$ sistem sayesinde matriks $30^{\circ}$ ye kadar paralellikten sapmaya imkan tanır. ${ }^{26}$

Choi ve arkadaşlarının $0^{\circ}, 15^{\circ}$ ve $30^{\circ}$ açıya sahip implantların O-ring ve EZ Lock tutucu sistemlerini kıyasladıkları çalışmada ${ }^{27}$, O-ring tutucu sisteminin tüm açılarda retansiyon kaybı olduğu; EZ Lock sisteminin $0^{\circ}, 15^{\circ}$ de $30^{\circ}$ açıya göre daha az retansiyon kaybı olduğu bildirilmiştir. Nogueira ve arkadaşları ${ }^{28}$ O-ring/ ball ataçman uyguladıkları hastalarda naylon matriks ve lastik matriksi kıyaslamışlar ve lastik matriks değişiminin daha az zaman gerektirdiğini bildirmişlerdir.

\section{ERA Tutucular}

ERA rezilien tipte bir stud tutucu tipidir. ERA ekstraradiküler olarak nitelendirilir, çünkü giriş rehberi implant desteği ve alvoler kretten daha yüksekte yer alır. Bu özellik tutucunun, kuvvetler karşısında dayanıklıı̆ını azaltır. Açılı yerleştirilmiş implantların paralelliklerini sağlamak için $5^{\circ}, 1^{\circ}$ ve $17^{\circ}$ açılara sahip açılı abutmanlar ve ayrıca düz abutmanlar içermektedir. ${ }^{29}$ Pelekanos ve arkadaşları $^{30}$ tek çene tam dişsiz 15 hastada 4 implanttan destek alarak uyguladıkları distal ERA tutuculu barlı overdenture protezlerin 5 senelik takibi sonucunda en yaygın komplikasyonun ERA tutucunun retantif parçasının değiştirilmesi olduğunu bildirmişlerdir.

\section{ZAAG Tutucular}

ZAAG tutucular, bileşeninin implant abutman içinin daha apikaline ve alveoler kretin daha yakınına pozisyonlandırılmış olmasından dolayı intraradiküler olarak nitelendirilir ve kuvvetlere karşı daha dayanıklıdır. $15^{\circ}$ ve $25^{\circ}$ açılı abutman seçeneği ile $10^{\circ}$ 'ye kadar açılanmayı tolere eden naylon patriks sayesinde, implantların birbirine paralelliğinin sağlanamadığı vakalarda uygulanabilir. ${ }^{31}$ Petropoulos ve arkadaşla- rının farklı tutucu tiplerinin retansiyonlarını karşılaştırdıkları çalışmada ${ }^{32}$ ZAAG tutucunun vertikal ve oblik kuvvetlere karşı en yüksek retantif değere sahip olduğu ve standart ball tutucunun (Nobel Biocare, Gothenburg, İsveç) oblik kuvvetlere karşı en düşük retantif değere sahip olduğu bildirilmiştir.

\section{Locator Tutucu}

Bu tutucu sistemi bağlantıyı implanta yerleşmiş locator abutman ve protez içerisine yerleştirilmiş patriks ile sağlar. Klinik uygulamasının ve laboratuar işlemlerinin kolay olması sebebiyle yaygın kullanılan bir sistemdir; mevcut proteze uygulanabilir. İmplant çevresindeki yumuşak dokuya uyum sağlayabilmesi için locator abutmanların 1-6 mm'lik değişik yüksekliklere sahip tipleri vardır. İmplant platformundan itibaren diş etinin ölçümü yapılarak uygun yükseklikte abutman seçimi yapılır. ${ }^{13} 3.17 \mathrm{~mm}$ toplam tutucu yüksekliğine sahip olan bu ataçman, arklar arası mesafenin az olduğu durumlarda veya aşırı konturlu protezlerde tercih edilmektedir. ${ }^{7}$ En yaygın problem naylon patriksinin bozulması ve retansiyonunun azalmasıdır. ${ }^{33}$ Locator tutucu sisteminde $10^{\circ}$ ve $20^{\circ}$ açılı abutman seçenekleri bulunmaktadır. İmplantlar arası $20^{\circ}$ ve $40^{\circ}$ açılanmayı tolere edebilen plastik patriksleri mevcuttur. Farklı retansiyon derecelerine sahip patriksleri vardır ve ayrımın kolay olması için birbirinden farklı renktedir (Şekil 7). ${ }^{34}$

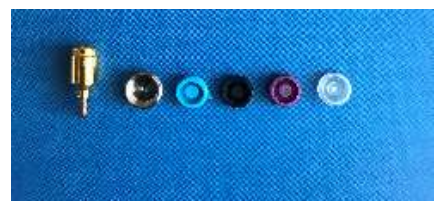

Şekil 7. Locator tutucu patriks ve matriksleri

Elsyad ve arkadaşlarının bar ve locator tutucuları kıyasladıkları çalışmada ${ }^{35}$, en yüksek retansiyon ve stabilite kaybı bar tutucuda ve sırasıyla şeffaf, pembe ve mavi renkli locator tutucularda görülmüştür. Yoo ve arkadaşlarının bar ve locator tutucuların implantlara iletilen stresi değerlendirdikleri çalışmada ${ }^{36}$, locator tutucunun çalışan taraftaki implantta çalışmayan tarafa göre daha fazla gerilim oluşturduğu; bar tutucunun ise çalışan ve çalışmayan her iki taraftaki implantta da gerilim oluşturduğu bildirilmiştir. Keis ve arkadaşları ${ }^{37}$ ball tutucu ve locator tutucu uyguladıkları çalışmada locator tutucuda daha fazla komplikasyon olduğunu belirtmişlerdir. Seo ve arkadaşlarının locator ataçman ve locator bar ataçman sistemlerini kıyasladıkları klinik çalışmada $^{38}$ locator ataçmanda daha fazla komplikas- 
yon gözlenmiştir. Lian ve arkadaşları ${ }^{39}$ stud tutucu ve bar tutucuları kıyaslamışlar ve tutucu sistemlerdeki komplikasyonlar arasında istatiksel olarak bir fark gözlememişlerdir. Krenmair ve arkadaşları ${ }^{40}$ bar tutucu ve locator tutucu uyguladıkları çalışmada locator tutucuların daha fazla bakım gerektirdiğini, tutuculukları açısından farkın görülmediğini belirtmişlerdir.

\section{Novaloc}

Novaloc tutucu, implant overdenture arasındaki bağlantıyı sağlayan stud türü bir tutucu sistemidir. Bu tutucu sistem novaloc ve locator abutmanlarla kullanılabilmektedir. Tutucuların yüzeyi, pürüzlülüğü en aza indiren ve tutucu parçaların direncini artıran elmas benzeri amorf karbon ile kaplanmıştır. Titanyum ya da polieterketon (PEEK)'dan oluşan silindirik bir patriks ile PEEK'den bir matriks arasında mekanik tutunma gerçekleşmektedir. Her biri beş farklı diş eti yüksek- liğine sahip düz ve $15^{\circ}$ lik dayanaklar implantlar ara- sındaki 700'ye kadar açı farklılıklarını tolere edebil- mektedir. Matriksleri 6 farklı renk seçeneğiyle göste- rilen farklı ağırlıklarda retansiyon parçalarından oluşur. Patriks ile matriks arasında bulunan küçük vida yuvası retansiyon parçasının herhangi bir gerilim olmadan genişlemesine izin vermektedir. ${ }^{41,42}$ Kliniğimizde uygulanan Novaloc tutucu örneği Şekil 8'de gösterilmiştir.

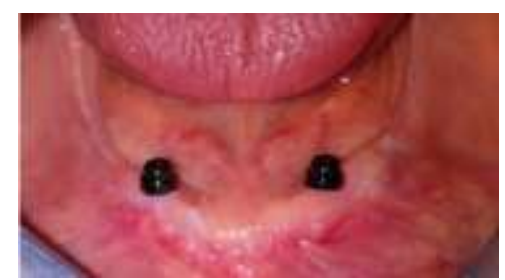

Şekil 8. Novaloc tutucu

\section{Optiloc}

Optiloc tutucu sistemi, pürüzsüz, aşınmaya karşı dayanıklı elmas sertliğinde bir yüzeye sahiptir. Novaloc sistemin tüm avantajlarına sahip olan optiloc sistem ball tutucularda olduğu gibi minimum yer gereksiniminde uygulanabilir (Şekil 9). Retansiyon parçaları PEEK'den üretilmiştir. Diğer matriks sistemlerinden farklı olarak bu sistemde matriks her zaman başlangıç pozisyonuna dönmektedir. İmplantlar arasındaki $40^{\circ}$ lik sapmalara kadar kullanılabilir. ${ }^{43}$

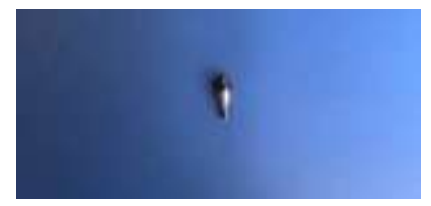

Şekil 9. Optiloc tutucu patriksi

\section{OT Equator}

Equator tutucu sistemi, paslanmaz çelik yuvalara sabitlenen dört farklı retansiyon parçası ve titanyum patriksten oluşmaktadır (Şekil 10). ERA ve locator tutucu sistemlerden daha küçük boyutlara sahip olan bu sistem dikey boyut kısıtlamalarının olduğu vakalarda uygulanabilmektedir. İmplantlar arasındaki 280'ye kadar açı farkını tolere edebilir. ${ }^{44}$ Marin ve arkadaşlarının O-Ring, mini ball ve equator sistemleri kıyasladıkları invitro çalışmada en yüksek retansiyon değeri, equator sistemde gözlenmiştir. ${ }^{45}$

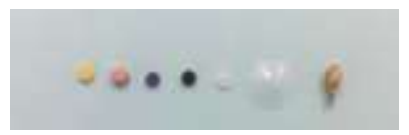

Şekil 10. OT Equator tutucu sistemi patriks ve matriksleri

\section{3-Mıknatıs Tutucular}

Diş hekimliğinde kullanılan mıknatıs tutucular, neodimyum-demir-boron veya samaryum-kobalt alaşımından olan mıktanıs ve abutmana vidalanacak şekilde yapılan ferromagnetik 'keeper' içerir. Protez ağza yerleştirildiğinde, protezdeki mıknatısla teması sonucu keeper, indüklenmiş mıknatıs haline geçer. Protez çıkartıldığında ise, keeper manyetize olmamış haline döner ve keeper çevresindeki manyetik alan yok olur. Bu alaşımlar ağızda korozyona uğradıkları için koruyucu kaplama uygulamak gerekir. ${ }^{46}$

Mıknatıs tutucular, giriş yoluna bakılmaksızın uygulanabilir; böylece farklı tutucularla da beraber kullanılabilir. Yaşı ve engelli hastalar için protezin takıp çıkartılması kolaydır. ${ }^{46}$ Spesifik bir giriş yoluna gerek duyulmaması, abutmanların birbirlerine paralelliğine gerek olmaması, yumuşak doku andırkatları varlığında uygulanabilmesi, potansiyel patolojik lateral veya rotasyon kuvvetlerinin kolaylıkla elimine edilerek maksimum abutman koruması sağlaması ve ball tutucularla birlikte maliyeti en düşük tutucular arasında yer alması gibi avantajlara sahiptir. Stud tutuculara göre daha fazla plak tutulumuna sebep olduğu ve çiğneme etkinliğinin iyi olmamasına bağlı olarak hasta konforu ve memnuniyetinde azalma gibi dezavantajlara da sahiptir. ${ }^{47}$ Takahashi ve arkadaşlarının ball, locator ve mıknatıs tutucuların makaslama gerilimlerini kıyasladıkları çalışmada ${ }^{48}$ en düşük makaslama kuvvetinin manyetik tutucuda; en yüksek makaslama kuvvetinin ball tutucuda olduğu bildirilmiştir. Zhang ve arkadaşlarının mıknatıs ve locator tutucuları kıyasladıkları çalışmada $^{49}$ en fazla komplikasyonun ilk yılda görüldüğü ve mıknatıs tutucuda daha fazla komplikasyon olduğu bildirilmiştir. 


\section{4-Teleskop Tutucular}

Teleskop tutucular çift kuron tasarımından oluşmaktadır. Alt yapı desteğe simante edilirken, buna uyumlu üst yapı ise hareketli proteze rijit bir şekilde bağlanmaktadır. Teleskop tutucuların alt yapısı destek dişi çürük ve termal iritasyonlardan korur. Tutuculuk ve stabilite esas olarak üst yapı ile sağlanır. Teleskop tutucular yapılarına göre rijit ve esnek olmak üzere ikiye ayrılırlar. Rijit olanlar yapılarından dolayı silindirik olarak da adlandırılabilmektedir. Esnek teleskopik tutucular paralel duvarlı bir yapıya sahiptir. Birincil ve ikincil kuron arasında okluzal kısımda yaklaşık 0,3mm'lik aralık bulunur. Bu aralık ile yumuşak doku reziliensi tolere edilir. Buna ilaveten matriks ile patriks arasındaki bu boşluk, çiğneme sırasında implantta ortaya çıkacak moment kuvvetini azaltı. ${ }^{50}$ Teleskop tutucuların sayısı, arktaki dağılımı ve eğimleri protezin tutuculuğuna ve stabilitesine etki eder. Splintleme etkisinin sabit protezdekine benzemesi, desteklerden biri kaybedildiğinde protezin yeniden düzenlenebilmesine olanak tanıması, destekler arası açılanmaları tolere edebilmesi ve oral hijyenin kolaylıkla sağlanabilmesi teleskop tutucuların avantajlarıdır. Parkinson gibi hastanın becerilerini olumsuz etkileyen sistemik rahatsılığa sahip geriatrik hastalar için etkili bir tedavi alternatifi olmakla birlikte, ball ve magnet tutucular kadar ekonomik değildir. ${ }^{51}$ Krenmair ve arkadaşlar. ${ }^{52}$, bar ve teleskop tutucuyu kıyasladıkları çalışmada kemik rezorpsiyonu ve cep derinliğinde anlamlı bir farklıı̆ın bulunmadığını ve plak tutulumunun bar tutuculu hastalarda daha fazla görüldüğünü bildirmişlerdir.

\section{SONUÇ}

Geleneksel tam protezlere kıyasla implant destekli hareketli protez uygulamaları retansiyon, stabilite ve hasta memnuniyeti açısından çok daha üstündür. Doğru hastada planlandığı ve uygulandığında değerli bir tedavi şeklidir. Hassas bağlantı tiplerinin her birinin kendine göre avantajları, dezavantajları, maliyetleri ve gereksinimleri vardır. Tutucu tipinin seçiminde hastanın ihtiyaçları, bakım kolaylığı, maliyeti, protez için yer gereksinimi, destek gereksinimleri ve olası ağız içi kuvvet dağıımı dikkate alınmalııı.

NOT: Calışmada herhangi bir yazar, kurum ya da kuruluş ile çıkar çatışması içerisinde bulunmamaktadır. Makale daha önce hiçbir yerde yayınlanmamış ve yayınlanmak üzere işlem görmemektedir

\section{KAYNAKLAR}

1. Misch CE. Dental Implant Protezler. Kutay Ö (Çev), 1. Basım. İstanbul: Nobel Tıp Kitabevi; 2009; Chapters: $1,13,14,19$.

2. Bueno-Samper A, Hernandez-Aliaga M, CalvoGuirado JL. The implant-supported milled bar overdenture: A literature review. Med Oral Patol Oral Cir Bucal 2010; 15: 375-8.

3. de Grandmont $P$, Feine JS, Taché R ve ark. Withinsubject comparisons of implant-supported mandibular prostheses: Psychometric evaluation. ] Dent Res 1994; 73: 1096-104.

4. Feine JS, Carlsson GE, Awad MA ve ark. The McGill consensus statement on overdentures. Mandibular two-implant overdentures as first choice standard of care for edentulous patients. Int $\mathrm{J}$ Oral Maxillofac Implants 2002; 17: 587-601.

5. Carlsson GE. Clinical morbidity and sequelae of treatment with complete dentures. J Prosthet Dent 1998; 79: 17-23.

6. Wismeijer D, Van Waas MAJ, Vermeeren JIJF, Muldel J, Kalk W. Patient satisfaction with implantsupported mandibular overdentures: A comparison of three treatment strategies with ITI-dental implants. Int J Oral Maxillofac Surg 1997; 26: 2637.

7. Pasciuta $M$, Grossmann $Y$, Finger IM. A prosthetic solution to restoring the edentulous mandible with limited interarch space using an implant-tissuesupported overdenture: A clinical report. J Prosthet Dent 2005; 93: 116-20.

8. Tokar E, Polat S, Uludağ B. Evaluation of effect of impression techniques to satisfaction of edentulous patients treated with implant-retained overdentures: A pilot study. Atatürk Üniv Diş Hek Fak Derg 2017; 27: 100-6.

9. Mericske-Stern R. Prosthodontic management of maxillary and mandibular overdentures. In: Feine JS, Carlsson GE, editors. Implant Overdentures: The Standard of Care for Edentulous Patients. 1st ed. Chicago: Quintessence Pub. 2003; Chapter 10: 83-96.

10. Batenburg RHK, Meijer HJA, Raghoebar GM, Vissink A. Treatment concept for mandibular overdentures supported by endosseous implants: A literature review. Int J Oral Maxillofac Implants 1998; 13: 539-45.

11. Spiekermann H, Donath $K$, Hassell T, Jovanovic $S$, Richter J. Color Atlas of Dental Medicine 
Implantology. 1st ed New York: Thieme Medical Pub. Inc. 1995; 245-72.

12. El-Dayem MAA, Assad AS, Sanad MEE, Mogahed SAAHM. Comparison of prefabricated and custommade bars used for implant-retained mandibular complete overdentures. Implant Dentistry 2009; 18: 501-11.

13. Laverty DP, Green D, Marrison D, Addy L, Thomas MBM. Implant retention systems for implantretained overdentures. Br Dent J 2017; 222: 34759.

14. Karoussis IK, Brägger U, Salvi GE, Bürgin W, Lang NP. Effect of implant design on survival and success rates of titanium oral implants: A 10-year prospective cohort study of the ITI $($ Dental Implant System. Clin Oral Implants Res 2004; 15 : 8-17.

15. Kim HY, Lee JY, Shin SW, Bryant SR. Attachment systems for mandibular implant overdentures: A systematic review. J Adv Prosthodont 2012; 4: 197-203.

16. Mericske-Stern R, Probst $D$, Fahrländer $F$, Schellenberg M. Within-subject comparison of two rigid bar designs connecting two interforaminal implants: Patients' satisfaction and prosthetic results. Clin Implant Dent Relat Res 2009; 11: 22837.

17. Elsyad MA, Emera RM, Ashmawy TM. Effect of different bar designs on axial and nonaxial retention forces of implant-retained maxillary overdentures: An in vitro study. Int J Oral Maxillofac Implants 2019; 34: 31-8.

18. Toia M, Wennerberg A, Torrisi P, Farina V, Corrà E, Cecchinato D. Patient satisfaction and clinical outcomes in implant supported overdentures retained by milled bars: Two-year follow-up. J Oral Rehabil 2019; 46: 624-33.

19. Rinke S, Rasing H, Gersdorff N, Buergers R, Roediger M. Implant-supported overdentures with different bar designs: A retrospective evaluation after 5-19 years of clinical function. J Adv Prosthodont 2015; 7: 338-43.

20. Shafie H. Principles of attachment selection. Clinical and Laboratory Manual of Implant Overdentures. Ames, Iowa: Blackwell Sci. 2007; Chapter 4: 31-4.

21. Ben-Ur Z, Gorfil C, Shifman A. Anterior implantsupported overdentures. Quintessence Int 1996; 27: 603-6.

22. Vasant $R$, Vasant MK. Retention systems for implant-retained overdentures. Dental Update 2013; 40: 28-31.

23. Ellis JS, Burawi G, Walls A, Thomason JM. Patient satisfaction with two designs of implant supported removable overdentures; ball attachment and magnets. Clin Oral Implants Res 2011; 20: 129398.

24. Sultana N, Bartlett DW, Suleiman M. Retention of implant-supported overdentures at different implant angulations: Comparing Locator and ball attachments. Clin Oral Implants Res 2017; 28: 1406-10.

25. Kim SM, Choi JW, Jeon YC, Jeong CM, Yun MJ, Lee $\mathrm{SH}$, Huh JB. Comparison of changes in retentive force of three stud attachments for implant overdentures. J Adv Prosthodont 2015; 7: 303-11.

26. Ortegón SM, Thompson GA, Agar JR, Taylor TD, Perdikis D. Retention forces of spherical attachments as a function of implant and matrix angulation in mandibular overdentures: An in vitro study. J Prosthet Dent 2009; 101: 231-8.

27. Choi JW, Bae JH, Jeong CM, Huh JB. Retention and wear behaviors of two implant overdenture studtype attachments at different implant angulations. J Prosthet Dent 2017; 117: 628-35.

28. Nogueira TE, Aguiar FMO, de Barcelos BA, Leles CR. A 2-year prospective study of single implant mandibular overdentures: Patient-reported outcomes and prosthodontic events. Clin Oral Implants Res 2018; 29: 541-50.

29. Porter JA, Petropoluos VC, Brunski JB. Comparison of load distribution for implant overdenture attachments. Int J Oral Maxillofac Implants 2002; 17: 651-62.

30. Pelekanos S, Sarafianou A, Tsirogiannis $P$, Kamposiora P, Papavasiliou G. A case series treatment outcome report following 5 years of implant overdenture treatment. Int J Prosthodont 2016; 29: 598-601.

31. Uludağ B, Polat S. İmplant destekli overdenture uygulamalarında kullanılan tutucular. Turkiye Klinikleri J Dental Sci-Special Topics 2010; 1:80-6.

32. Petropoulos VC, Mante FK. Comparison of retention and strain energies of stud attachments for implant overdentures. J Prosthodont 2011; 20: 286-93.

33. Vere J, Hall D, Patel R, Wragg P. Prosthodontic maintenance requirements of implant-retained overdentures using the locator attachment system. Int J Prosthodont 2012; 25: 392-4. 
34. Schneider AL, Kurtzman GM. Restoration of divergent free-standing implants in the maxilla. J Oral Implantol 2002; 28: 113-6.

35. ELsyad MA, Dayekh MA, Khalifa AK. Locator versus bar attachment effect on the retention and stability of implant-retained maxillary overdenture: An in vitro study. J Prosthodont 2017; 28: 627-36.

36. Yoo JS, Kwon KR, Noh K, Lee H, Paek J. Stress analysis of mandibular implant overdenture with locator and bar/clip attachment: Comparative study with differences in the denture base length. J Adv Prosthodont 2017; 9: 143-51.

37. Kleis WK, Kämmerer PW, Hartmann S, Al-Nawas B, Wagner W. A comparison of three different attachment systems for mandibular two-implant overdentures: One-year report. Clin Implant Dent Relat Res 2010; 12: 209-18.

38. Seo YH, Bae EB, Kim JW, Lee SH, Yun MJ, Jeong $\mathrm{CM}$, Huh JB. Clinical evaluation of mandibular implant overdentures via Locator implant attachment and Locator bar attachment. J Adv Prosthodont 2016; 8: 313-20.

39. Lian M, Zhao K, Wang F, Huang W, Zhang X ve ark. Stud vs bar attachments for maxillary fourimplant-supported overdentures: 3-to 9-year results from a retrospective study. International J Oral Maxillofac Implants 2019; 34: 936-46.

40. Krennmair G, Seemann R, Fazekas A, Ewers R, Piehslinger $\mathrm{E}$. Patient preference and satisfaction with implant-supported mandibular overdentures retained with ball or locator attachments: A crossover clinical trial. Int J Oral Maxillofac Implants 2012; 27: 1560-8.

41. De Souza RF, Bedos C, Esfandiari S, Makhoul NM, Dagdeviren $D$ ve ark. Single-implant overdentures retained by the Novaloc attachment system: Study protocol for a mixed-methods randomized crossover trial. Trials 2018; 19: 243-54.

42. Lee CK, Agar JR. Surgical and prosthetic planning for a two-implant-retained mandibular overdenture: A clinical report. J Prosthet Dent 2006;95: 102-5.

43. Optiloc sistem. Erişim:_(https://www.straumann. com/medentika/dk/en/dentistry/mps-multi-

platform-systems/optiloc.html). Erişim tarihi: 04/07/2019.

44. Mínguez-Tomás $\mathrm{N}$, Alonso-Pérez-Barquero J, Fernández-Estevan L, Vicente-Escuder Á, J. SelvaOtaolaurruchi E. In vitro retention capacity of two overdenture attachment systems: Locator ${ }^{\circledR}$ and
Equatorß. J Clin Exp Dent 2018;10: 681-86.

45. Marin DOM, Leite ARP, Oliveira Junior NMD, Paleari AG, Pero AC, Compagnoni MA. Retention force and wear characteristics of three attachment systems after dislodging cycles. Braz Dent J 2018;29: 57682.

46. Preiskel HW, Preiskel A. Precision attachments for the 21st century. Dental Update 2009; 36: 221-7.

47. Ceruti P, Bryant SR, Lee JH, MacEntee MI. Magnetretained implant-supported overdentures: Review and 1-year clinical report. J Can Dent Assoc 2010; 76: 1-6.

48. Takahashi T, Gonda T, Maeda Y. Effect of attachment type on denture strain in maxillary implant overdentures: Part 1. Overdenture with palate. International J Oral Maxillofac Implants 2017; 32: 370-82.

49. Zhang Y, Chow L, Siu A, Fokas G, Chow TW, Mattheos N. Patient-reported outcome measures (PROMs) and maintenance events in 2-implant-supported mandibular overdenture patients: A 5-year prospective study. Clin Oral Implants Res 2019; 30: 261-76.

50. Heckmann SM, Schrott A, Graef F, Wichmann MG, Weber HP. Mandibular two-implant telescopic overdentures. Clin Oral Implants Res 2004; 15: 560-9.

51. Heckmann SM, Heckmann JG, Weber HP. Clinical outcomes of three Parkinson's disease patients treated with mandibular implant overdentures. Clin Oral Implants Res 2000; 11: 566-71.

52. Krennmair G, Sütö D, Seemann R, Piehslinger E. Removable four implant-supported mandibular overdentures rigidly retained with telescopic crowns or milled bars: A 3-year prospective study. Clin Oral Implants Res 2012; 23: 481-8.

\author{
Yazışma Adresi \\ Dt. Mustafa SOLMAZGÜL \\ Gazi Üniversitesi Diş Hekimliği Fakültesi \\ Emek Mah. Bişkek Cd. (8. Cd.) 1. Sk. No:4 \\ 06510 Çankaya-ANKARA \\ Tel: 05322057697 \\ E-mail: mstfslmzgl@gmail.com
}

